\title{
Pulmonary balloon valvuloplasty in the palliation of complex cyanotic congenital heart disease
}

\author{
O Stümper, J F Piéchaud, P Bonhoeffer, D Bonnet, Y Aggoun, D Sidi, J Kachaner
}

\begin{abstract}
Objective-To assess the value of pulmonary balloon valvuloplasty in the interim palliation of complex congenital heart disease and pulmonary stenosis in children, who often require numerous palliative operations before definitive surgical repair.

Methods-Evaluation of pulmonary balloon valvuloplasty procedures performed over a five year period in 18 patients (age 8 days-29 years; mean $5 \cdot 5$ years) with complex cyanotic congenital heart disease.

Results-After pulmonary balloon valvuloplasty oxygen saturation increased from a mean (SD) of $69(7.5) \%$ to $83(7.0) \%(P<$ $0 \cdot 001)$. Mean pulmonary artery pressure increased from a mean (SD) of $11.3(3 \cdot 8)$ $\mathrm{mm} \mathrm{Hg}$ to $15.7(3.9) \mathrm{mm} \mathrm{Hg}(P<0.001)$. Transient complete atrioventricular block occurred in one patient. No other complications were encountered. In 5 patients $(28 \%)$ there was an inadequate improvement in cyanosis compared with preprocedure values $(72(4 \cdot 7) \% v 66(8 \cdot 1) \%)$. Reasons for failure were increasing infundibular stenosis in three and inadequate mixing in one child. In 13 patients (72\%) pulmonary balloon valvuloplasty gave adequate interim palliation over a mean follow up of $1 \cdot 1(1 \cdot 3)$ years. Oxygen saturation was $81(5 \cdot 6) \%$ at last follow up compared with $70(7 \cdot 3) \%$ before pulmonary balloon valvuloplasty $(P<0.001)$. Conclusion-Pulmonary balloon valvuloplasty is a safe and effective technique in the palliation of patients with complex cyanotic congenital heart disease associated with pulmonary valve stenosis.
\end{abstract}

(Heart 1996;76:363-366)

Service de Cardiologie Pédiatrique, Hôpital Necker/Enfants-

Malades, Paris, France O Stümper

JF Piéchaud

P Bonhoeffer

D Bonnet

Y Aggoun

D Sidi

J Kachaner

Correspondence to:

Prof Jean Kachaner, Service de Cardiologie Pédiatrique, Hôpital Necker/EnfantsMalades, 149 rue de Sèvres, 75015 Paris, France.

Accepted for publication 3 May 1996 Keywords: pulmonary valvuloplasty; pulmonary stenotion.

Complex cyanotic congenital heart disease is frequently associated with severe valvar and subvalvar pulmonary stenosis that restricts pulmonary blood flow. Despite the advances in surgical technique over the past decade, most children presenting with such lesions will initially require the creation of a systemic-topulmonary artery shunt in order to establish adequate pulmonary blood flow. Frequently, further surgical shunt procedures have to be carried out before complete repair or definitive palliation can be accomplished later during childhood.

Pulmonary balloon valvuloplasty is the technique of choice in the treatment of isolated pulmonary valve stenosis. ${ }^{1-3}$ Numerous studies have documented the value of pulmonary balloon valvuloplasty in the interim palliation of patients with tetralogy of Fallot, ${ }^{4-6}$ although its routine clinical use remains controversial. Boucek and colleagues ${ }^{7}$ were the first to report results of pulmonary balloon valvuloplasty in three patients with complex cyanotic congenital heart disease. However, to date no larger detailed studies have been reported.

In this report we describe our experience with pulmonary balloon valvuloplasty in a series of 18 patients with complex congenital heart disease and its impact on patient management.

\section{Patients and methods}

Over a five year period pulmonary balloon valvuloplasty was performed in 18 patients with complex cyanotic congenital heart disease associated with severe pulmonary valve stenosis. All patients had abnormalities involving the atrioventricular and/or the ventriculoarterial junction of the heart (table 1). Five had double discordance (congenitally corrected transposition), seven had a univentricular heart, and six had complex forms of transposition of the great arteries. Fifteen patients had atrial situs solitus, two had situs inversus, and one child had right atrial isomerism. Four children had dextrocardia. All had a patent femoral vein and inferior vena cava, and no patient was found to have an azygos continuation of the inferior vena cava.

Age at pulmonary balloon valvuloplasty was mean (SD) $5.5(6.9)$ years (range 8 days-29 years). Weight at the time of procedure was mean (SD) $16 \cdot 1 \quad(13.3) \mathrm{kg}$ (range 2.6$58 \mathrm{~kg}$ ).

In $11(61 \%)$ of 18 patients pulmonary tive procedure, whereas seven patients (39\%) had undergone previous surgical palliation (systemic-to-pulmonary artery shunt in six and bilateral cavopulmonary shunts in one patient). One patient (case 2) underwent a second balloon valvuloplasty 2.6 years after the first.

INDICATIONS

Indications for pulmonary balloon valvulo- 
Table 1 Patient data

\begin{tabular}{|c|c|c|c|c|c|c|c|c|c|c|c|c|}
\hline \multirow[b]{2}{*}{ No } & \multirow{2}{*}{$\begin{array}{l}\text { Age } \\
(y r)\end{array}$} & \multirow{2}{*}{$\begin{array}{l}\text { Weight } \\
(\mathrm{kg})\end{array}$} & \multirow[b]{2}{*}{ Diagnosis } & \multirow{2}{*}{$\begin{array}{l}\text { Atrial } \\
\text { situs }\end{array}$} & \multirow{2}{*}{$\begin{array}{l}\text { Dextro- } \\
\text { cardia }\end{array}$} & \multirow{2}{*}{$\begin{array}{l}\text { Previous } \\
\text { palliation }\end{array}$} & \multirow{2}{*}{$\begin{array}{l}\text { B/A } \\
\text { ratio }\end{array}$} & \multicolumn{3}{|c|}{ Saturations } & \multicolumn{2}{|c|}{$P A$ pressures } \\
\hline & & & & & & & & Pre & Post & $F / U$ & Pre & Post \\
\hline 1 & 1.9 & $8 \cdot 0$ & DORV, TGA & Solitus & + & - & $1 \cdot 3$ & 58 & 62 & 65 & 8 & 17 \\
\hline 2 & $4 \cdot 6$ & $14 \cdot 1$ & DILV, TGA & Solitus & & - & 0.9 & 63 & 85 & 68 & 8 & 17 \\
\hline & $7 \cdot 2$ & $24 \cdot 2$ & (repeat PBV) & & & & $1 \cdot 1$ & 68 & 91 & 80 & 15 & 22 \\
\hline 3 & $9 \cdot 2$ & 23.7 & DORV, TGA & Solitus & & Bilat BTS & $1 \cdot 1$ & 81 & 89 & 82 & 17 & 20 \\
\hline 4 & 1.5 & $10 \cdot 2$ & cAVSD, DORV & Solitus & & - & $1 \cdot 0$ & 57 & 88 & 78 & 8 & 13 \\
\hline 5 & $5 \cdot 5$ & 13.6 & CcTGA, VSD & Inversus & + & - & $1 \cdot 1$ & 68 & 90 & 73 & 12 & 16 \\
\hline 6 & $2 \cdot 3$ & $11 \cdot 7$ & ccTGA, VSD & Solitus & & - & 0.9 & 65 & 80 & 76 & 7 & 13 \\
\hline 7 & 0.02 & $2 \cdot 6$ & DILV, TGA & Solitus & & - & $1 \cdot 1$ & 62 & 83 & 83 & 8 & 22 \\
\hline 8 & $2 \cdot 9$ & $12 \cdot 1$ & cAVSD, DORV, TGA & RAI & & - & 1.0 & 72 & 82 & 85 & 18 & 18 \\
\hline 9 & $29 \cdot 5$ & 58 & TGA, VSD & Solitus & & - & $1 \cdot 1$ & 73 & 84 & 83 & 10 & 15 \\
\hline 10 & $7 \cdot 3$ & $25 \cdot 3$ & TA, VSD & Solitus & & Bilat CPS & 1.0 & 83 & 89 & 88 & 8 & 10 \\
\hline 11 & $14 \cdot 1$ & $33 \cdot 2$ & DILV, TGA & Solitus & & Left BTS & $1 \cdot 0$ & 68 & 80 & 82 & 18 & 22 \\
\hline 12 & $8 \cdot 3$ & $23 \cdot \overline{2}$ & ccTGA, MA, VSD & Solitus & + & Left BTS & $1 \cdot 2$ & 70 & 78 & 76 & 11 & 17 \\
\hline 13 & $4 \cdot 5$ & $13 \cdot \overline{6}$ & ccTGA, VSD & Solitus & + & Bilat BTS & 10 & 79 & 80 & 78 & 12 & 12 \\
\hline 14 & $3 \cdot 3$ & $14 \cdot 0$ & ccTGA, VSD & Inversus & & Left BTS & 1.0 & 78 & 93 & 90 & 10 & 11 \\
\hline 15 & $0 \cdot 2$ & $2 \cdot 8$ & DILV & Solitus & & - & 0.9 & 62 & 84 & 73 & 7 & 11 \\
\hline 16 & 0.4 & $5 \cdot 2$ & DILV, TGA & Solitus & & - & $1 \cdot 1$ & 70 & 81 & 80 & 16 & 17 \\
\hline 17 & 0.8 & $6 \cdot 8$ & DILV, TGA & Solitus & & - & $1 \cdot 2$ & 63 & 75 & 73 & 11 & 12 \\
\hline 18 & $0 \cdot 3$ & $4 \cdot 1$ & TGA, VSD & Solitus & & Left BTS & 1.0 & 67 & 79 & 76 & 11 & 13 \\
\hline
\end{tabular}

B/A ratio, ratio of balloon to pulmonary valve annulus; Bilat, bilateral; BTS, modified Blalock-Taussig shunt; cAVSD, complete atrioventricular septal defect; ccTGA, congenitally corrected transposition of the great arteries; CPS, bidirectional cavopulmonary shunt; DILV, double inlet left ventricle; DORV, double outright atrial isomerism; TA, tricuspid atresia; TGA, transposition of the great arteries; VSD, ventricular septal defect.

All patients had severe valvar pulmonary stenosis.

plasty were: firstly, complexity of potential surgical repair, making increased patient size desirable; secondly, increasing cyanosis despite interim surgical palliation; or, thirdly, profound cyanosis associated with severe polycythaemia.

\section{CATHETERISATION}

All procedures were performed with local anaesthesia and sedation using intravenous diazepam. After percutaneous cannulation of the femoral vein 100 units of heparin per kilogram bodyweight was administered. A complete haemodynamic evaluation and appropriate angiographic studies were conducted. In three patients a Multi-Track angiographic catheter was used to perform angiograms at the level of the stenotic valve over a previously placed guidewire. The diameter of the pulmonary valve annulus was measured at the level of the hinge points of the stenotic valve. Balloon valvuloplasty was performed with low profile monofoil balloons in

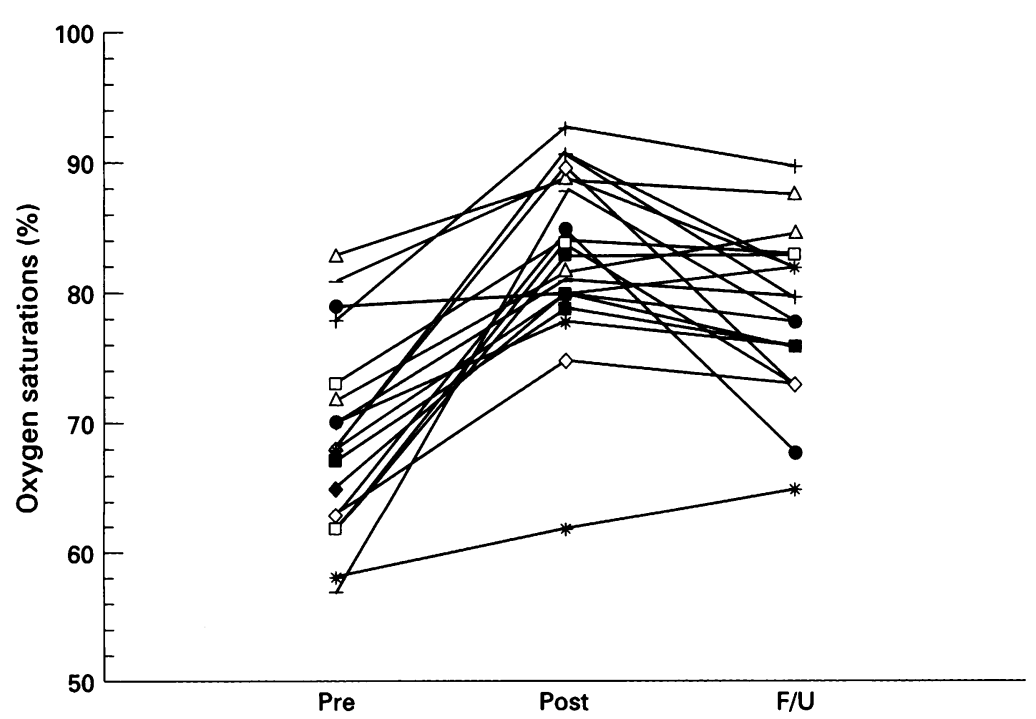

Change in oxygen saturation after pulmonary balloon valvuloplasty. $F / U$, oxygen saturation at last follow up or before surgical intervention; pre, pre procedure value; post, post procedure value.
16 patients. Trefoil balloons were used in two patients early in the experience. Initially, gentle balloon inflation was performed to observe the typical waist formation caused by the stenotic valve in order to confirm optimal balloon positioning. Gradual submaximal inflation of the balloon was carried out, with close monitoring of arterial oxygen saturations between each inflation. Balloon dilatation was completed as judged by the disappearance of the waist, and repeat haemodynamic studies were carried out to assess the changes in pulmonary arterial pressures and arterial oxygen saturations.

FOLLOW UP

All patients underwent detailed follow up. Increasing or persistent cyanosis with percutaneous oxygen saturations measuring less than $75 \%$ together with increase in symptoms and haemoglobin concentrations were used as criteria to proceed to further surgical palliation, repair, or repeat pulmonary valvuloplasty.

\section{STATISTICAL ANALYSIS}

Data analysis was performed using standard software. Where applicable, data were expressed as mean values together with standard deviation (SD) or $95 \%$ confidence intervals $(95 \% \mathrm{CI})$. Paired and unpaired Student's $t$ tests were used to test for differences after balloon valvuloplasty and between groups. A $P$ value $<0.05$ was regarded as significant.

\section{Results}

Nineteen pulmonary balloon valvuloplasty procedures were performed in 18 patients. One patient (case 2 (table 1)) had a second procedure $2 \cdot 6$ years after the first.

Mean arterial oxygen saturation at the beginning of the procedure was $69(7 \cdot 5) \%$. After balloon dilatation of the stenotic pulmonary valve oxygen saturations (table 2) increased by a mean (SD) of $14(7 \cdot 8) \%$ to 83 $(7.0) \% \quad(P<0.001)$. The balloon to pulmonary valve annulus ratio was $1.05(0.2)$ (range $0 \cdot 9-1 \cdot 3$ ). After dilatation there was a significant increase in pulmonary arterial mean 


\begin{tabular}{ll}
\hline Follow up & $\begin{array}{l}\text { Subsequent } \\
\text { surgery }\end{array}$ \\
\hline $3 \mathrm{wk}$ & Rastelli \\
$2 \cdot 6 \mathrm{yr}$ & Bilat CPS \\
$1 \cdot 5 \mathrm{yr}$ & - \\
$5 \cdot 2 \mathrm{yr}$ & Left BTS \\
$5 \mathrm{mnth}$ & Left BTS \\
$5 \mathrm{dy}$ & - \\
$1 \cdot 1 \mathrm{yr}$ & - \\
$1 \mathrm{yr}$ & - \\
$6 \mathrm{mnth}$ & - \\
$9 \mathrm{mnth}$ & - \\
$7 \mathrm{mnth}$ & - \\
$1 \mathrm{yr}$ & Fontan \\
$4 \mathrm{mnth}$ & Rastelli \\
$3 \mathrm{mnth}$ & - \\
$2 \mathrm{mnth}$ & Left BTS \\
$2 \mathrm{wk}$ & - \\
$4 \mathrm{mnth}$ & Right CPS \\
$3 \mathrm{wk}$ & - \\
$2 \mathrm{mnth}$ & \\
\hline
\end{tabular}

pressures (mean (SD) $15 \cdot 7 \quad(3.9) \mathrm{mm} \mathrm{Hg}$ (range $11-22 \mathrm{~mm} \mathrm{Hg}$ ) $v 11.3(3.8) \mathrm{mm} \mathrm{Hg}$ (range $7-18 \mathrm{~mm} \mathrm{Hg})$ ) $(\mathrm{P}<0.001)$.

Percutaneous oxygen saturations at last follow up or before further intervention were mean (SD) $78(6.4) \%(P<0.001 v$ preprocedure values)

\section{FAILURES}

In five of the 18 patients $(28 \% ; 95 \%$ CI $16 \%$ to $43 \%$ ) there was no persistent adequate improvement in cyanosis after the procedure (figure). Percutaneous oxygen saturation (mean (SD)) before surgical intervention was $72(4 \cdot 7) \%$ (table 2 ). Two patients (cases 1 and 13) underwent definitive repair, and three patients (cases 5, 15, and 17) underwent a palliative shunt procedure. There was one hospital death (case 15). Mean time interval (SD) between pulmonary balloon valvuloplasty and surgical intervention was 31 days (range 5-96 days).

\section{SUCCESSES}

In 13 of the 18 patients $(72 \% ; 95 \%$ CI $57 \%$ to $84 \%$ ) an adequate persistent improvement was achieved by pulmonary balloon valvuloplasty. In one patient (case 2) increasing cyanosis developed $2 \cdot 6$ years after the initial pulmonary valvuloplasty procedure. Because residual severe valvar pulmonary stenosis was found, a second valvuloplasty procedure was performed. At a mean (SD) follow up interval of $1 \cdot 1(1 \cdot 3)$ years (range $0 \cdot 4-5 \cdot 2$ years) percutaneous oxygen saturation was $81(5 \cdot 6) \%(P$ $<0.001 v$ pre procedure values). Further surgical procedures were carried out in three of these patients (cases 2, 4, and 12) four to 18 months after the valvuloplasty procedure. Two of these patients underwent a bidirectional cavopulmonary shunt procedure (case 2 ) or a Fontan procedure (case 12), with no adverse effects despite the fact that immediate postdilatation pulmonary artery mean pressures were 22 and $17 \mathrm{~mm} \mathrm{Hg}$ respectively.

There were no significant differences between the group of patients with failed and successful pulmonary balloon valvuloplasty procedures, in terms of the principal type of congenital cardiac lesion, age, weight, pulmonary arterial pressures, and pre and immediate post dilatation arterial oxygen saturations. However, these subgroups were small

Table 2 Oxygen saturations before pulmonary balloon valvuloplasty, immediately after, and at last follow up or reintervention

\begin{tabular}{|c|c|c|c|c|c|c|}
\hline & $\begin{array}{l}\text { Mean }(S D) \\
(\%)\end{array}$ & Range (\%) & $95 \% C I$ & & $P$ values & \\
\hline \multicolumn{7}{|c|}{ Overall study population $(n=18)$} \\
\hline $\begin{array}{l}\text { Pre PBV } \\
\text { Post PBV } \\
\text { Follow up }\end{array}$ & $\begin{array}{l}69(7 \cdot 5) \\
83(7 \cdot 0) \\
78(6 \cdot 4)\end{array}$ & $\begin{array}{l}57-83 \\
62-93 \\
65-90 \\
\text { Failed PBV } n\end{array}$ & $\begin{array}{l}65-72 \\
80-86 \\
75-81 \\
=5)\end{array}$ & \} & $<0.001$ & $<0.001$ \\
\hline $\begin{array}{l}\text { Pre PBV } \\
\text { Post PBV } \\
\text { Follow up }\end{array}$ & $\begin{array}{l}66(8 \cdot 1) \\
78(11) \\
72(4 \cdot 7)\end{array}$ & $\begin{array}{l}58-79 \\
62-90 \\
65-78\end{array}$ & $\begin{array}{l}59-73 \\
69-87 \\
68-76\end{array}$ & \} & $<0.05$ & NS \\
\hline $\begin{array}{l}\text { Pre PBV } \\
\text { Post PBV } \\
\text { Follow up }\end{array}$ & $\begin{array}{l}70(7 \cdot 3) \mathrm{Su} \\
84(4 \cdot 9) \\
81(5 \cdot 6)\end{array}$ & $\begin{array}{l}\text { cessful PBV } \\
57-83 \\
78-93 \\
76-90\end{array}$ & $\begin{array}{l}=13) \\
66-74 \\
82-87 \\
77-84\end{array}$ & \} & $<0.001$ & $<0.001$ \\
\hline
\end{tabular}

PBV, pulmonary balloon valvuloplasty; Statistical analysis using Student's $t$ test. (five and 13 patients respectively). Failures were related to severe infundibular pulmonary stenosis in three patients and inadequate intracardiac shunting in one patient (case 1).

\section{COMPLICATIONS}

One patient (case 13) with atrial situs solitus, double discordance (congenitally corrected transposition) and dextrocardia experienced transient complete heart block, which resolved spontaneously. No other complications were encountered.

\section{Discussion}

Severe pulmonary valve stenosis is a frequent finding in patients with complex cyanotic congenital heart disease. Most often infants and children will undergo one or more systemicto-pulmonary artery shunt procedures, before definitive repair or palliation can be accomplished. However, the principal complication of modified Blalock-Taussig shunts is distortion of the native pulmonary artery system. ${ }^{89}$ Such lesions have particular consequences in patients who are only candidates for a Fontantype procedure as the definitive surgical palliation.

Relief of the pulmonary valve stenosis will increase anterograde pulmonary blood flow in such patients. This could provide both adequate relief of cyanosis and be beneficial for pulmonary arterial growth, without the risk of distortion of the native pulmonary arterial system. Such a technique can be used to augment pulmonary blood flow in the presence of a bidirectional cavopulmonary shunt, ${ }^{10-12}$ as in one patient (case 10) in our series. In contrast to surgical valvotomy this technique allows close monitoring of both arterial oxygen saturations and resultant pulmonary artery pressures during the procedure.

We reviewed our experience with pulmonary balloon valvuloplasty in the interim palliation of patients with complex cyanotic congenital heart disease. Indications for such a procedure were based on individual patient history. Because of promising results early on during the study period, we decided to proceed more readily to primary balloon valvuloplasty rather than to perform a surgical shunt procedure. This is reflected by the rather short follow up and the younger patient age in the second half of the series.

Rather than perform gradual balloon dilatation with increasing balloon sizes we elected to adopt a technique of progressive dilatation of the stenotic pulmonary valve. After each submaximal inflation arterial oxygen saturations were reassessed so as to estimate the achieved increase in pulmonary blood flow. The initial balloon size was chosen to match the pulmonary valve annulus, similar to current practice for aortic balloon valvuloplasty. Balloons more than 1.2 times the size of the pulmonary valve annulus were used in only three patients. In two patients no adequate immediate result could be obtained. In one patient (case 1) this was related to transposition physiology: there was inadequate mixing because the atrial septal 
defect was small. In this case we think that the addition of a blade septostomy would have given an adequate result. The other patient with a poor immediate result had double discordance and severe valvar and subvalvar pulmonary stenosis (case 13). After inflation of a balloon the same size as the pulmonary valve annulus, complete heart block developed and the procedure was abandoned. The next day the patient had regained normal atrioventricular conduction. The other three patients with inadequate relief of cyanosis who required early surgical intervention developed severe infundibular stenosis (unresponsive to $\beta$ blockade in two) after the relief of the valvar stenosis.

In all patients there was an increase in pulmonary arterial mean pressures after balloon dilatation, in keeping with the increase in pulmonary blood flow. However, procedural factors such as the administration of large flush and contrast volumes may have contributed to an increase in post-procedural pressures. We did not routinely reevaluate pulmonary vascular resistances at the end of the procedure. Only one patient with mean pulmonary artery pressure of more than $18 \mathrm{~mm} \mathrm{Hg}$ had a postprocedural arterial oxygen saturation of less than $82 \%$. We do not believe that pulmonary balloon valvuloplasty in these patients will prevent a subsequent Fontan-type repair.

\section{CONCLUSIONS}

The results of this study suggest that pulmonary balloon valvuloplasty can provide adequate interim palliation in patients with complex cyanotic congenital heart disease who have severe valvar pulmonary stenosis. Wider use of this technique is likely to reduce the need for systemic-to-pulmonary artery shunt procedures in infants with such lesions.

OS was supported by a senior research fellowship (Human capital and mobility No ERB CH BGCT 930373) by the European Community.

1 Kan JS, White RI, Mitchell SE, Gardner TJ. Percutaneous balloon valvuloplasty: a new method for treating congenital pulmonary valve stenosis. $N$ Engl f Med 1982;307: 540-5.

2 Rey C, Marache P, Francart C, Dupuis C. Percutaneous transluminal balloon valvuloplasty of congenital pulmonary valve stenosis, with a special report on infants and neonates. $\mathcal{F} \mathrm{Am}$ Coll Cardiol 1988;11:815-20.

3 McCrindle BW for the VACA Registry Investigators. Independent predictors of long-term results after balloon pulmonary valvuloplasty. Circulation 1994;89:1751-9.

4 Oureshi SA, Kirk CR, Lamb RK, Arnold R, Wilkinson JL Balloon dilatation of the pulmonary valve in the first year of life in patients with tetralogy of Fallot: a preliminary of life in patients with tetralogy

5 Piéchaud JF, Delogu AB, Iserin L, Aggouh Y, Cohen L Sidi D. Traitement palliatif de la tétralogie de Fallot par dilatation infundibulo-pulmonaire percutanée. Arch Mal Coeur 1994;87:573-9.

6 Sluysmans T, Neven B, Rubay J, Linkermans J, Ordest C, Mucurmbitsi J, et al. Early balloon dilatation of the pulmonary valve in infants with tetralogy of Fallot Circulation 1995;91:1506-11.

7 Boucek MM, Webster HE, Orsmond GS, Ruttenberg HD Balloon pulmonary valvotomy: palliation for cyanotic heart disease. Am Heart $₹$ 1988; 115:318-22.

8 Kay PH, Capuani A, Franks R, Lincoln C. Experience with the modified Blalock-Taussig shunt using polytetrafluothe modified Blalock-Taussig shunt using polyte

9 Bove EL, Kohman L, Sereika S, Byrum CJ, Kavey RW, Blackman MS, et al. The modified Blalock-Taussig shunt: analysis of the adequacy and duration of palliation. Circulation 1987;76(suppl III):19-23.

10 Frommelt MA, Frommelt PC, Berger S, Pelech AN, Lewis DA, Tweddell JS, et al. Does an additional source of pulmonary blood flow alter the outcome after a cavopulmonary shunt. Circulation 1995;92(suppl II):II-240-4.

11 Webber SA, Horvath P, LeBlanc JG, Slavik Z, Lamb RK, Monzo JL, et al. Influence of competitive pulmonary blood flow on the bidirectional superior cavopulmonary shunt. Circulation 1995;92(suppl II):279-86.

12 Uemura T, Anderson RH. Use of the bidirectional Glenn procedure in the presence of forward flow from the ventricles dure in the presence of forward flow from the ventricles
to the pulmonary arteries. Circulation 1995;92(suppl to the pulm
II) $: 228-32$ 